\title{
CONTROLE QUÍMICO EM PÓS-EMERGÊNCIA DE ESPÉCIES DE BRACHIARIA EM TRÊS ESTÁDIOS VEGETATIVOS
}

\author{
R.P. Marques ${ }^{1}$, R.A. Rodella ${ }^{2}$, D. Martins ${ }^{1}$ \\ ${ }^{1}$ Universidade Estadual Paulista, Faculdade de Ciências Agronômicas, Departamento de Produção e Melho- \\ ramento Vegetal, Rua José Barbosa de Barros, 1780,CEP18610-307, Botucatu, SP, Brasil.E-mail: renatapm_84@ \\ hotmail.com
}

\section{RESUMO}

Oobjetivo do presente trabalho foi relacionar a eficiência do controle químico em pós-emergência de Brachiaria decumbens Stapf. (capim-braquiária) e Brachiaria plantaginea Hitchc. (capim-marmelada) por meio de herbicidas inibidores da enzima ACCase em função do estádio de desenvolvimento da planta, visando fornecer subsídios para o manejo químico dessas espécies daninhas. A semeadura de $B$. decumbens e $B$. plantaginea foi feita em vasos plásticos contendo solo e mantidos em casa de vegetação. Para a avaliação do controle químico foram testados os herbicidas ( $\mathrm{gha}^{-1}$ ): fluazifop-p-butil a 150, haloxyfop-methyl a 50 e sethoxydim a 230. Os herbicidas foram aplicados em três estádios de desenvolvimento da planta: estádio 1 (plantas com 4-6 folhas aos 15 dias após a emergência), estádio 2 (plantas com 3-4 perfilhos aos 23 dias após a emergência) e estádio 3 (plantas adultas no início do florescimento aos 48 dias após a emergência). As avaliações de controle foram feitas 4, 7, 10, 14, 17, 21, 24 e 28 dias após a aplicação dos herbicidas. O estádio de desenvolvimento das duas espécies de Brachiaria foi determinante na eficiência de controle proporcionado pelos diferentes herbicidas estudados. Verificou-se que o herbicida sethoxydim foi mais eficiente no controle das espécies de Brachiaria, nos três estádios de desenvolvimento estudados.

PALAVRAS-CHAVE: Capim-braquiária, capim-marmelada, gramíneas, inibidores da ACCase.

\begin{abstract}
CHEMICAL CONTROL IN POST-EMERGENCE OF SPECIES OF BRACHIARIA IN THREE VEGETATIVE STAGES. The aim of this study was to correlate the chemical control efficacy in post-emergence of Brachiaria decumbens Stapf. (signal grass) and Brachiaria plantaginea Hitchc. (alexandergrass) through ACCase-inhibitor enzyme herbicide application in function of the stage of development of the plant in order to contribute to the chemical management of these weed species. $B$. decumbens and B. plantaginea were sown in plastic pots filled with soil and kept in a greenhouse. For chemical control evaluation, the following herbicides were tested ( $\mathrm{g} \mathrm{ha} \mathrm{h}^{-1}$ ): fluazifop-p-butyl at 150, haloxyfop-methyl at 50, and sethoxydim at 230. The herbicides were applied in all three plant development phases: stage 1 (plants presenting 4-6 leaves at 15 days after emergence), stage 2 (plants presenting 3-4 tillers at 23 days after emergence), and stage 3 (adult plants in the beginning of flowering at 48 days after emergence). Evaluations were done at 4, 7, 10,14, 17, 21, 24, and 28 days after herbicide application. The developmental stage of the two Brachiaria species was instrumental in the efficiency of the control provided by different herbicides. Sethoxydim was the most efficient herbicide in controlling Brachiaria species in the three evaluated development stages.
\end{abstract}

KEY WORDS: ACCase inhibitors, Alexandergrass, grasses, signal grass.

\section{INTRODUÇÃO}

Para o controle de plantas daninhas perenes e anuais da família Poaceae em condições de pósemergência, os herbicidas inibidores da enzima ACCase (Acetil Co-A Carboxilase) são comumente utilizados. Existe uma ampla quantidade de herbicidas recomendados e registrados no Ministério da Agricultura para o controle dessas espécies infestantes, destacando-se ofluazifop-p-butil, haloxyfopmethyl e sethoxydim, os quais são recomendados para o controle de gramíneas infestantes deculturas.

${ }^{2}$ Universidade Estadual Paulista, Instituto de Biociências de Botucatu, Departamento de Botânica, Botucatu, SP, Brasil. 
O controle feito com herbicidas aplicados em pós-emergência está sujeito à influência de fatores relacionados com o tamanho das plantas no instante da aplicação, ondeespécies do mesmo gênero podem se comportar de maneira diferente aos tratamentos (Rizzardi; Fleck, 2004; CARVAlho et al., 2006). Esses mesmos autores avaliaram que o sucesso do controle dos herbicidas aplicados em pós-emergência em Amaranthus spp., Bidens spp. e Sida rhombifolia foi reduzido quando essas plantas não se encontravam nas fases iniciais do seu desenvolvimento.

FLECK et al. (1997) afirmaram que o controle de Brachiaria plantaginea (capim-marmelada) em soja foi reduzido de $99 \%$ para $86 \%$, devido ao atraso da aplicação de 28 para 36 dias após a emergência da cultura. Por sua vez, o controle efetuado precocemente permite que ele seja realizado quando as plantas daninhas apresentam menor desenvolvimento vegetativo e maior suscetibilidade ao herbicida. Atraso no controle das plantas daninhas aumenta o período de convivência das culturas com estas plantas, o que pode aumentar as perdas em produtividade de grãos.

CRAWFORD; ZAMBRYSKY (2001) observaram que os tecidos mais novos possuem a capacidade de transportar moléculas maiores. Isso pode explicar por que as plantas tornam-se menos suscetíveis aos herbicidas à medida que avança seu estádio de desenvolvimento.

Deste modo, após a diferenciação e a maturação dos tecidos, a concentração de lignina na lamela mediana e na parede primária é mais elevada que na parede secundária (AKIN;CHESSON, 1989). A formação da parede secundária, entre outros fatores, também limita a translocação de herbicidas por plantas mais velhas, por ser menos permeável e mais espessa que a parede primária. Esses são fatores que contribuem para a necessidade de utilizar doses maiores de herbicidas para controlar plantas mais velhas, até certo momento do desenvolvimento (CHAMEL, 1988), reforçando a necessidade do controle em pós-emergência ser realizado nas fases iniciais do desenvolvimento dessas gramíneas, como em Brachiaria. decumbens (capim-braquiária) e B. plantaginea.

O objetivo do presente trabalho foi relacionar a eficiência do controle químico em pós-emergência de B. decumbens (capim-braquiária)e Brachiaria plantaginea (capim-marmelada) por meio deherbicidas inibidores da enzima ACCase em função do estádio de desenvolvimento da planta, visandofornecer subsídios para o manejo químico dessas espécies daninhas.

\section{MATERIAL E MÉTODOS}

O experimento foi conduzido no Núcleo de Pesquisas Avançadas em Matologia (NUPAM), do Departamento de Produção Vegetal da Faculdade de Ciências Agronômicas de Botucatu, UNESP, utilizando-se $B$. decumbens e $B$. plantaginea, duas espécies consideradas daninhas. As sementes de $B$. decumbens e de B. plantaginea foram semeadas em vasos plásticos de $4 \mathrm{~L}$ de capacidade, com cinco repetições, contendo solo e mantidos em casa de vegetação. Após a emergência das plântulas foi efetuado um desbaste, em ambas as espécies, deixando cinco plântulas por vaso.

Estudaram-se três estádios de desenvolvimento das plantas daninhas: Estádio 1 (plantas com 4-6 folhas aos 15 dias após a emergência), Estádio 2 (plantas com 3-4 perfilhos aos 23 dias após a emergência) e Estádio 3 (planta adulta no início do florescimento aos 48 dias após a emergência). Foram testados os três herbicidas inibidores da enzima ACCase: fluazifop-p-butil a $150 \mathrm{~g} \mathrm{ha}^{-1}$, haloxyfop-methyl a 50 $\mathrm{g} \mathrm{ha}^{-1} \mathrm{e}$ sethoxydim a $230 \mathrm{~g} \mathrm{ha}^{-1}$, misturado com óleo mineral Assist a 1,5 $\mathrm{L} \mathrm{ha}^{-1}$, além de uma testemunha sem aplicação de herbicidas.

Para a aplicação dos herbicidas foi utilizado um pulverizador estacionário equipado com barra de aplicação, contendo quatro pontas de pulverização tipo jato plano XR 11002VS. O consumo de calda foi de $200 \mathrm{~L} \mathrm{ha}^{-1}$.

As avaliações de controle foram efetuadas aos 4,7, $10,14,17,21,24$ e 28 dias após a aplicação (DAA) dos herbicidas. Para o primeiro estádio de desenvolvimento da planta as avaliações foram realizadas até o $14^{\circ} \mathrm{DAA}$, para o segundo estádio até o $21^{\circ} \mathrm{DAA}$, enquanto para o terceiro estádio de desenvolvimento as avaliações foram realizadas até o $28^{\circ}$ dia após a aplicação dos herbicidas. Para efetuar as avaliações utilizou-se uma escala visual e percentual de notas, na qual a nota " 0 " consiste em nenhum controle e a nota " 100 " corresponde à morte das plantas.

A massa seca da parte aérea foi determinada ao final das avaliações de controle de cada estádio de desenvolvimento das duas espécies de Brachiaria estudadas. Para determinação da massa seca, coletou-se a parte aérea das plantas de cada vaso e delas foram acondicionadas em sacos de papel; em seguida, foram levadas a uma estufa de circulação forçada de ar mantida a $60 \pm 2^{\circ} \mathrm{C}$, até atingir massa constante, sendo posteriormente pesadas em balança analítica de precisão $(0,01 \mathrm{~g})$.

Os resultados obtidos para porcentagem de controle e para a massa seca da parte aérea foram submetidos à análise de variância pelo teste $\mathrm{F}$, e as médias dos tratamentos foram comparadas pelo teste de Tukey a $5 \%$ de probabilidade, sendo os dados de porcentagens transformados em arcsen $\sqrt{x}$.

\section{RESULTADOS E DISCUSSÃO}

Na Tabela 1, para plantas de $B$. decumbens no estádio de 4-6 folhas, nota-se um elevado nível de 
controle já aos 4 dias após aplicação (DAA) dos herbicidas sem diferença entre os tratamentos, bem como um progressivo controle para os demais dias de avaliação após a aplicação deles. Contudo, aos 7 DAA observa-se diferença entre os herbicidas sethoxydim e haloxyfop-methyl quando comparados com ofluazifop-p-butil, sendo que os dois primeiros herbicidas apresentaram melhor controle das plantas de B. decumbens nesteestádio de desenvolvimento das plantas. Aos 10 DAA, os três herbicidas mostraramse eficiente no controle total desta espécie, causando a morte delas aos 14 DAA.

Segundo SmedA; Putnam (1990), este comportamento é esperado, uma vez que a eficácia desses herbicidas aplicados em pós-emergência é máxima quando se tem plantas em estágios iniciais de desenvolvimento (3-5 folhas), e que esse fator é determinante para o bom desempenho dos herbicidas aplicados em pós-emergência precoce.

Na Tabela 2observa-se, com relação ao estádio de 3-4 perfilhos de B. decumbens, comportamento distinto para os três herbicidas aos 4, 7, 14 e 21 DAA, sendo que o herbicida sethoxydim apresentou o melhor desempenho em relação aos demais; o herbicida haloxyfop-methyl foi melhor no controle das plantas do que o fluazifop-p-butil, exceto aos 7 DAA, onde ambos apresentaram desempenho estatisticamente semelhante. Nas plantas de B. decumbens, no estádio de3-4 perfilhos, oúnico herbicida causador de morte nas plantas, aos 21 DAA, foi o sethoxydim.

VIDAL et al. (2006), trabalhando com uma outra gramínea infestante de lavouras, obtiveram bons resultados de controle em populações selvagens e em biótipos com suspeita de resistência em Eleusine indica, com o uso de herbicidas inibidores da ACCase. O herbicida sethoxydim aplicado até o estádio de 1 perfilho apresentou bom controle das plantas de E. indica selvagem; enquanto o uso de sethoxydim, butroxydim, fenoxaprop, propaquizafop e cyhalofop não controlaram eficientemente as plantas com suspeita de resistência a esses herbicidas, porém, este biótipo foi eficazmente controlado com clethodim, fluazifop-p-butil, haloxyfop-methyl e quizalofop.

Tabela 1 - Porcentagem de controle de plantas de Brachiaria decumbens no Estádio 1 de desenvolvimento (plantas com 4-6 folhas), em diferentes períodos após a aplicação dos herbicidas. Botucatu, SP, 2007/2008.

\begin{tabular}{|c|c|c|c|c|}
\hline \multirow{2}{*}{ Tratamentos } & \multirow{2}{*}{ (doses) } & \multicolumn{3}{|c|}{ Dias após a aplicação dos herbicidas } \\
\hline & & 4 & 7 & 14 \\
\hline testemunha & & $0,0 \mathrm{a}$ & $0,0 \mathrm{a}$ & 0,0 \\
\hline fluazifop-p-butil & $\left(150 \mathrm{~g} \mathrm{ha}^{-1}\right)$ & $76,0 \mathrm{~b}$ & $90,2 \mathrm{~b}$ & 100,0 \\
\hline haloxyfop-methyl & $\left(50 \mathrm{~g} \mathrm{ha}^{-1}\right)$ & $74,6 \mathrm{~b}$ & $97,6 \mathrm{c}$ & 100,0 \\
\hline sethoxydim & $\left(230 \mathrm{~g} \mathrm{ha}^{-1}\right)^{1}$ & $79,6 \mathrm{~b}$ & $99,0 \mathrm{c}$ & 100,0 \\
\hline F tratamento & & $763,83 * *$ & $546,70 * *$ & - \\
\hline d.m.s & & 4,49 & 7,00 & - \\
\hline $\mathrm{CV}(\%)$ & & 5,40 & 6,44 & - \\
\hline
\end{tabular}

*significativo a $5 \%$ de probabilidade.

** significativo a $1 \%$ de probabilidade.

${ }^{1}$ Adicionou-se 1,5 L. ha de óleo mineral Assist.

Médias seguidas de mesma letra, na coluna, não diferem estatisticamente pelo teste Tukey a 5\% de probabilidade.

Tabela 2 - Porcentagem de controle de plantas de Brachiaria decumbens no Estádio 2 de desenvolvimento (plantas com 3-4), em diferentes períodos após a aplicação dos herbicidas. Botucatu, SP, 2007/2008.

\begin{tabular}{|c|c|c|c|c|c|}
\hline \multirow{2}{*}{ Tratamentos } & \multirow{2}{*}{ (doses) } & \multicolumn{4}{|c|}{ Dias após a aplicação dos herbicidas } \\
\hline & & 4 & 7 & 14 & 21 \\
\hline testemunha & & $0,0 \mathrm{a}$ & $0,0 \mathrm{a}$ & $0,0 \mathrm{a}$ & $0,0 \mathrm{a}$ \\
\hline fluazifop-p-butil & $\left(150 \mathrm{~g} \mathrm{ha}^{-1}\right)$ & $10,0 \mathrm{~b}$ & $52,0 \mathrm{~b}$ & $87,4 \mathrm{~b}$ & $90,8 \mathrm{~b}$ \\
\hline haloxyfop-methyl & $\left(50 \mathrm{~g} \mathrm{ha}^{-1}\right)$ & $15,4 \mathrm{c}$ & $49,0 \mathrm{~b}$ & $92,6 \mathrm{c}$ & $93,6 \mathrm{c}$ \\
\hline sethoxydim & $\left(230 \mathrm{~g} \mathrm{ha}^{-1}\right)^{1}$ & $20,0 \mathrm{~d}$ & $83,0 \mathrm{c}$ & $100,0 \mathrm{~d}$ & $100,0 \mathrm{~d}$ \\
\hline $\mathrm{F}$ tratamento & & $1298,27^{* *}$ & $220,34^{* *}$ & $2535,73^{* *}$ & $4672,91^{* *}$ \\
\hline d.m.s & & 1,34 & 7,60 & 3,21 & 2,40 \\
\hline $\mathrm{CV}(\%)$ & & 4,35 & 10,71 & 3,03 & 2,22 \\
\hline
\end{tabular}

*significativo a $5 \%$ de probabilidade.

**significativo a $1 \%$ de probabilidade.

${ }^{1}$ Adicionou-se 1,5 L. ha de óleo mineral Assist.

Médias seguidas de mesma letra, na coluna, não diferem estatisticamente pelo teste Tukey a 5\% de probabilidade. 
Tabela 3 - Porcentagem de controle de plantas de Brachiaria decumbens no Estádio 3 de desenvolvimento (planta adulta no início do florescimento), em diferentes períodos após a aplicação dos herbicidas. Botucatu, SP, $2007 / 2008$.

\begin{tabular}{|c|c|c|c|c|c|c|}
\hline \multirow{2}{*}{ Tratamentos } & \multirow{2}{*}{ (doses) } & \multicolumn{5}{|c|}{ Dias após a aplicação dos herbicidas } \\
\hline & & 4 & 7 & 14 & 21 & 28 \\
\hline testemunha & & $0,0 \mathrm{a}$ & $0,0 \mathrm{a}$ & $0,0 \mathrm{a}$ & $0,0 \mathrm{a}$ & $0,0 \mathrm{a}$ \\
\hline fluazifop-p-butil & $\left(150 \mathrm{~g} \mathrm{ha}^{-1}\right)$ & $0,0 \mathrm{a}$ & $0,4 \mathrm{a}$ & $4,2 \mathrm{~b}$ & $11,8 \mathrm{~b}$ & $9,2 \mathrm{~b}$ \\
\hline haloxyfop-methyl & $\left(50 \mathrm{~g} \mathrm{ha}^{-1}\right)$ & $0,0 \mathrm{a}$ & $0,4 \mathrm{a}$ & $17,6 \mathrm{c}$ & $54,0 \mathrm{c}$ & $57,0 \mathrm{c}$ \\
\hline sethoxydim & $\left(230 \mathrm{~g} \mathrm{ha}^{-1}\right)^{1}$ & $0,0 \mathrm{a}$ & $2,6 \mathrm{~b}$ & $36,6 \mathrm{~d}$ & $76,0 \mathrm{~d}$ & $75,4 \mathrm{~d}$ \\
\hline F tratamento & & - & $12,77^{*}$ & $63,47^{* *}$ & $100,04^{* *}$ & $131,46^{* *}$ \\
\hline d.m.s & & - & 5,13 & 8,10 & 11,10 & 9,92 \\
\hline $\mathrm{CV}(\%)$ & & - & 83,50 & 24,75 & 19,11 & 17,23 \\
\hline
\end{tabular}

*significativo a $5 \%$ de probabilidade.

**significativo a $1 \%$ de probabilidade.

${ }^{1}$ Adicionou-se 1,5 L. ha de óleo mineral Assist.

Médias seguidas de mesma letra, na coluna, não diferem estatisticamente pelo teste Tukey a $5 \%$ de probabilidade.

Tabela 4 - Porcentagem de controle de plantas de Brachiaria plantaginea no Estádio 1 de desenvolvimento (plantas com 4-6), em diferentes períodos após a aplicação dos herbicidas. Botucatu, SP, 2007/2008.

\begin{tabular}{|c|c|c|c|c|c|}
\hline \multirow{2}{*}{ Tratamentos } & \multirow{2}{*}{ (doses) } & \multicolumn{4}{|c|}{ Dias após a aplicação dos herbicidas } \\
\hline & & 4 & 7 & 10 & 14 \\
\hline testemunha & & $0,0 \mathrm{a}$ & $0,0 \mathrm{a}$ & $0,0 \mathrm{a}$ & $0,0 \mathrm{a}$ \\
\hline fluazifop-p-butil & $\left(150 \mathrm{~g} \mathrm{ha}^{-1}\right)$ & $62,0 \mathrm{~b}$ & $86,0 \mathrm{~b}$ & $99,0 \mathrm{~b}$ & $99,2 \mathrm{~b}$ \\
\hline haloxyfop-methyl & $\left(50 \mathrm{~g} \mathrm{ha}^{-1}\right)$ & $79,0 \mathrm{c}$ & $99,8 \mathrm{c}$ & $100,0 \mathrm{c}$ & $100,0 \mathrm{c}$ \\
\hline sethoxydim & $\left(230 \mathrm{~g} \mathrm{ha}^{-1}\right)^{1}$ & $83,0 \mathrm{c}$ & $100,0 \mathrm{c}$ & $100,0 \mathrm{c}$ & $100,0 \mathrm{c}$ \\
\hline F tratamento & & $753,43^{* *}$ & $1639,10^{* *}$ & $2337,91^{* *}$ & $2812,86^{* *}$ \\
\hline d.m.s & & 4,50 & 4,23 & 3,09 & 3,39 \\
\hline $\mathrm{CV}(\%)$ & & 5,53 & 3,79 & 3,71 & 2,81 \\
\hline
\end{tabular}

*significativo a $5 \%$ de probabilidade.

**significativo a $1 \%$ de probabilidade.

${ }^{1}$ Adicionou-se 1,5 L. ha de óleo mineral Assist.

Médias seguidas de mesma letra, na coluna, não diferem estatisticamente pelo teste Tukey a $5 \%$ de probabilidade.

Na Tabela 3 nota-se um processo mais lento no controle das plantas adultas de $B$. decumbens, sem sintomas aparentes decontroleaos4DAA,em relaçãoaos demais estádios de desenvolvimento. Aos 7 DAA somente o herbicida sethoxydim diferiu estatisticamente dos demais, sendo que os demais tratamentos não diferiram entre si. No entanto, nos demais períodos de avaliação, todos os tratamentos diferiram entre si, sendo que o herbicidasethoxydimapresentou melhor desempenho no controle, seguido pelo haloxyfop-methyl e pelo fluazifop-p-butil. Os herbicidas não causaram a morte das plantas neste estádio de desenvolvimento.

De fato, além da formulação do herbicida, a idade da planta é fundamental para a eficiência no controle em pós-emergência, concordando com CRAWFORD; ZAMBRYSKY (2001) ao afirmarem que os tecidos mais novos apresentam capacidade de transportar moléculas maiores, explicando assim porque as plantas se tornam menos suscetíveis aos herbicidas à medida que avança seu estádio de desenvolvimento.
Considerando as doses geralmente recomendadas, a literatura relata que, na aplicação tardia do fluazifop-p-butil, o controle tende a ser menos eficaz, uma vez que as plantas estão mais desenvolvidas e, portanto, com maior capacidade de recuperação (Smeda; Putnam, 1990).

Com relação às plantas de $B$. plantaginea (Tabela 4), no estádio de 4-6 folhas, a porcentagem de controle apresentada demonstra rápidos sintomas de controle no decorrer dos dias após a aplicação dos produtos. Os herbicidas haloxyfop-methyl e sethoxydim comportaram-se de maneira idêntica estatisticamente em todos os períodos de avaliação, diferindo nestes períodos do herbicida fluazifopp-butil. No entanto, os três herbicidas causaram a morte das plantas aos 14 DAA.

FLECK et al. (2008) trabalharam com outro herbicida inibidor da enzima ACCase e estudaram a possibilidade de redução de doses dos herbicidas clethodim, para o controle de capim-marmelada em pós-emergência, concluindo que, até o estádio 
de desenvolvimento que vai de apenas uma folha até 9 perfilhos, a redução da dose em até $38 \%$ e em apenas uma aplicação controla a planta infestante sem ocorrer perda de eficiência ou comprometimento da produtividade de grãos de soja. No entanto, o atraso na aplicação de clethodim, quando as plantas de capim-marmelada já desenvolveram 14 perfilhos e as plantas de soja alcançaram o estádio V7 a V8, reduziu a produtividade de grãos da cultura.

Verifica-se também, na Tabela 5, comportamento distinto dos herbicidas no controle das plantas de $B$. plantaginea, no estádio de 3-4 perfilhos, aos 4 DAA, sendo que o tratamento com herbicida sethoxydim apresentou melhor desempenho em todos os períodos deavaliação, causandoa morte das plantasaos 14DAA, diferindo estatisticamente dos demais herbicidas, em todos os períodos deavaliação. Já, o herbicidafluazifopp-butilcontrolou as plantas de B. plantaginea demaneira idêntica ao haloxyfop-methyl aos 7 DAA; entretanto, nos demais períodos deavaliação, esteúltimo herbicida apresentou melhores níveis de controle.
Osucesso douso deherbicidasempós-emergência depende da habilidade do produtor em determinar o momento correto de controlar as plantas daninhas. Nesse aspecto, muitas vezes, com a integração de práticas de manejo, as doses de herbicidas podem ser reduzidas e, ainda assim, promover controle satisfatório dessas plantas (MOHLER, 2001; NAZARKO et al., 2005).

Para a porcentagem de controle das plantas adultas de B. plantaginea, Tabela 6 , constata-se que não houve controle aos 4 DAA. Aos 7 DAA, o herbicida fluazifop-p-butil comportou-se de maneira intermediária em relação aos demais, sendo que o tratamento com o herbicida sethoxydim sobressaiuse aos demais. Aos 14 DAA, os herbicidas fluazifopp-butil e haloxyfop-methyl não diferiram entre si, apresentando maior controle o herbicida sethoxydim. Aos 21 e 28 DAA, todos os tratamentos diferiram entre si. No último dia de avaliação de controle (28 DAA), somente o herbicida sethoxydim apresentou controle satisfatório.

Tabela 5 - Porcentagem de controle de plantas de Brachiaria plantaginea no Estádio 2 de desenvolvimento (plantas com 3-4 perfilhos), em diferentes períodos após a aplicação dos herbicidas. Botucatu, SP, 2007/2008.

\begin{tabular}{|c|c|c|c|c|c|}
\hline \multirow{2}{*}{ Tratamentos } & \multirow{2}{*}{ (doses) } & \multicolumn{4}{|c|}{ Dias após a aplicação dos herbicidas } \\
\hline & & 4 & 7 & 14 & 21 \\
\hline testemunha & & $0,0 \mathrm{a}$ & $0,0 \mathrm{a}$ & $0,0 \mathrm{a}$ & $0,0 \mathrm{a}$ \\
\hline fluazifop-p-butil & $\left(150 \mathrm{~g} \mathrm{ha}^{-1}\right)$ & $30,0 \mathrm{~b}$ & $83,0 \mathrm{~b}$ & $91,6 \mathrm{~b}$ & $97,6 \mathrm{~b}$ \\
\hline haloxyfop-methyl & $\left(50 \mathrm{~g} \mathrm{ha}^{-1}\right)$ & $36,4 \mathrm{c}$ & $85,0 \mathrm{~b}$ & $95,0 \mathrm{c}$ & $99,8 \mathrm{c}$ \\
\hline sethoxydim & $\left(230 \mathrm{~g} \mathrm{ha}^{-1}\right)^{1}$ & $52,0 \mathrm{~d}$ & $98,4 \mathrm{c}$ & $100,0 \mathrm{~d}$ & $100,0 \mathrm{~d}$ \\
\hline F tratamento & & $1024,20 * *$ & $777,35^{* *}$ & $3906,38^{* *}$ & $767,76^{* *}$ \\
\hline d.m.s & & 2,54 & 5,39 & 2,63 & 6,39 \\
\hline $\mathrm{CV}(\%)$ & & 4,85 & 5,50 & 2,42 & 5,39 \\
\hline
\end{tabular}

*significativo a $5 \%$ de probabilidade.

**significativo a $1 \%$ de probabilidade.

${ }^{1}$ Adicionou-se 1,5 L. ha de óleo mineral Assist.

Médias seguidas de mesma letra, na coluna, não diferem estatisticamente pelo teste Tukey a 5\% de probabilidade.

Tabela 6 - Porcentagem de controle de plantas de Brachiaria plantaginea no Estádio 3 de desenvolvimento (planta adulta no início do florescimento), em diferentes períodos (dias) após a aplicação dos herbicidas. Botucatu, SP, $2007 / 2008$.

\begin{tabular}{|c|c|c|c|c|c|c|}
\hline \multirow{2}{*}{ Tratamentos } & \multirow{2}{*}{ (doses) } & \multicolumn{5}{|c|}{ Dias após a aplicação dos herbicidas } \\
\hline & & 4 & 7 & 14 & 21 & 28 \\
\hline testemunha & & $0,0 \mathrm{a}$ & $0,0 \mathrm{a}$ & $0,0 \mathrm{a}$ & $0,0 \mathrm{a}$ & $0,0 \mathrm{a}$ \\
\hline fluazifop-p-butil & $\left(150 \mathrm{~g} \mathrm{ha}^{-1}\right)$ & $0,0 \mathrm{a}$ & $6,0 \mathrm{bc}$ & $17,2 \mathrm{~b}$ & $20,8 \mathrm{~b}$ & $16,6 \mathrm{~b}$ \\
\hline haloxyfop-methyl & $\left(50 \mathrm{~g} \mathrm{ha}^{-1}\right)$ & $0,0 \mathrm{a}$ & $3,8 \mathrm{~b}$ & $26,4 \mathrm{~b}$ & $41,6 \mathrm{c}$ & $43,4 \mathrm{c}$ \\
\hline sethoxydim & $\left(230 \mathrm{~g} \mathrm{ha}^{-1}\right)^{1}$ & $0,0 \mathrm{a}$ & $9,6 \mathrm{c}$ & $68,0 \mathrm{c}$ & $85,4 \mathrm{~d}$ & $87,4 \mathrm{~d}$ \\
\hline F tratamento & & - & $53,97^{* *}$ & $146,35^{* *}$ & $140,23^{* *}$ & $1054,61^{* *}$ \\
\hline d.m.s & & - & 4,17 & 7,67 & 9,70 & 3,96 \\
\hline $\mathrm{CV}(\%)$ & & - & 21,82 & 15,30 & 15,93 & 6,20 \\
\hline
\end{tabular}

*significativo a 5\% de probabilidade.

**significativo a $1 \%$ de probabilidade.

${ }^{1}$ Adicionou-se 1,5 L. ha de óleo mineral Assist.

Médias seguidas de mesma letra, na coluna, não diferem estatisticamente pelo teste Tukey a 5\% de probabilidade. 
Vários pesquisadores têm informado sobre a eficácia de herbicidas aplicados em pós-emergência no controle de B. plantaginea. FLECKet al. (1995) encontraram reduções de 97,5 e $96,5 \%$ das plantas quando utilizaram, respectivamente, $90 \mathrm{~g} \mathrm{ha}^{-1}$ de haloxyfopmethyl e $220 \mathrm{~g} \mathrm{ha}^{-1}$ de sethoxydim, na cultura da soja com densidade de 420 plantas $m^{-2}$. FLECK et al. (1997), trabalhando com duas dosagens de clethodim (60 e $120 \mathrm{~g} \mathrm{ha}^{-1}$ ) e 95 plantas $\mathrm{m}^{-2}$, observaram reduções na população de B. plantaginea da ordem de $99 \%$ ao aplicar a maior dosagem.

Com relação à massa seca das plantas de $B$. decumbens, na Tabela 7 verifica-se a ocorrência de diferença significativa da massa seca das plantas testemunhas, no estádio de 4-6 folhas e no estádio de 3-4 perfilhos, quando comparadas com as plantas expostas aos herbicidas. No estádio de planta adulta, a massa seca destas plantas apresentou diferença estatística entre os herbicidas fluazifop-p-butil e sethoxydim, enquanto o herbicida haloxyfop-methyl manteve os valores de massa seca sob níveis intermediários, quandocomparados aos demais tratamentos; porém, todos os tratamentos diferiram significativamente da testemunha.

Na Tabela 8, pode-se constatar que os valores da massa seca das plantas de B. plantaginea, expostas aos herbicidas testados no estádio de 4-6 folhas e no de 3-4 perfilhos, diferiram estatisticamente da testemunha. No estádio de planta adulta essa espécie, quando exposta ao herbicida fluazifop-p-butil, não diferiu da testemunha, enquanto os demais herbicidas não diferiram significativamente entre si, diferindo apenas do tratamento sem aplicação de herbicidas.

Tabela 7 - Massa seca média da parte aérea de cinco plantas por vaso de Brachiaria decumbens, em três estádios (E1-E2E3) de desenvolvimento da planta, avaliada, respectivamente, aos 14, 21 e 28 dias após a aplicação dos herbicidas. Botucatu, SP, 2007/2008.

\begin{tabular}{|c|c|c|c|c|}
\hline \multirow{3}{*}{ Tratamentos } & \multirow{3}{*}{ (doses) } & \multicolumn{3}{|c|}{ Estádios de desenvolvimento } \\
\hline & & 4-6 folhas & 3-4 perfilhos & planta adulta \\
\hline & & \multicolumn{3}{|c|}{ Massa seca (gramas) } \\
\hline testemunha & & $9,49 \mathrm{a}$ & $21,81 \mathrm{a}$ & $53,69 a$ \\
\hline fluazifop-p-butil & $\left(150 \mathrm{~g} \mathrm{ha}^{-1}\right)$ & $0,44 \mathrm{~b}$ & $1,51 \mathrm{~b}$ & $33,11 \mathrm{~b}$ \\
\hline haloxyfop-methyl & $\left(50 \mathrm{~g} \mathrm{ha}^{-1}\right)$ & $0,17 \mathrm{~b}$ & $1,26 \mathrm{~b}$ & $27,17 \mathrm{bc}$ \\
\hline sethoxydim & $\left(230 \mathrm{~g} \mathrm{ha}^{-1}\right)^{1}$ & $0,13 \mathrm{~b}$ & $0,79 \mathrm{~b}$ & $22,56 \mathrm{c}$ \\
\hline F tratamento & & $1592,80^{* *}$ & $241,79 * *$ & 36,40 ** \\
\hline d.m.s & & 0,46 & 2,68 & 9,21 \\
\hline CV (\%) & & 10,13 & 23,44 & 14,91 \\
\hline
\end{tabular}

*significativo a $5 \%$ de probabilidade.

**significativo a $1 \%$ de probabilidade.

${ }^{1}$ Adicionou-se 1,5 L. ha de óleo mineral Assist.

Médias seguidas de mesma letra, na coluna, não diferem estatisticamente pelo teste Tukey a $5 \%$ de probabilidade.

Tabela 8 - Massa seca média da parte aérea de cinco plantas por vaso de Brachiaria plantaginea, em três estádios (E1-E2E3) de desenvolvimento da planta, avaliada, respectivamente, aos 14, 21 e 28 dias após a aplicação dos herbicidas. Botucatu, SP, 2007/2008.

\begin{tabular}{|c|c|c|c|c|}
\hline \multirow{3}{*}{ Tratamentos } & \multirow{3}{*}{ (doses) } & \multicolumn{3}{|c|}{ Estádios de desenvolvimento } \\
\hline & & 4-6 folhas & 3-4 perfilhos & planta adulta \\
\hline & & \multicolumn{3}{|c|}{ Massa seca (gramas) } \\
\hline testemunha & & $9,66 \mathrm{a}$ & $24,15 \mathrm{a}$ & $56,38 \mathrm{a}$ \\
\hline fluazifop-p-butil & & $0,45 \mathrm{~b}$ & 2,28 & $44,04 \mathrm{ab}$ \\
\hline haloxyfop-methyl & $\left(150 \mathrm{~g} \mathrm{ha}^{-1}\right)$ & $0,24 \mathrm{~b}$ & $1,65 \mathrm{~b}$ & $30,30 \mathrm{~b}$ \\
\hline sethoxydim & $\left(50 \mathrm{~g} \mathrm{ha}^{-1}\right)$ & $0,19 \mathrm{~b}$ & $1,03 \mathrm{~b}$ & $28,61 \mathrm{~b}$ \\
\hline F tratamento & $\left(230 \mathrm{~g} \mathrm{ha}^{-1}\right)^{1}$ & $2623,47^{* *}$ & $151,73^{* *}$ & $10,55^{*}$ \\
\hline d.m.s & & 0,37 & 3,69 & 16,22 \\
\hline CV $(\%)$ & & 7,81 & 28,09 & 22,53 \\
\hline
\end{tabular}

*significativo a $5 \%$ de probabilidade.

**significativo a $1 \%$ de probabilidade.

${ }^{1}$ Adicionou-se 1,5 L. ha de óleo mineral Assist.

Médias seguidas de mesma letra, na coluna, não diferem estatisticamente pelo teste Tukey a $5 \%$ de probabilidade. 
Os herbicidas podem apresentar diferentes níveis de controle de plantas daninhas, em função de espécies presentes na área, estádio de desenvolvimento, dose do herbicida e condições de aplicação e de ambiente. $\mathrm{O}$ controle eficiente de plantas daninhas com o uso de herbicidas em pós-emergência depende, sobretudo, do estádio de desenvolvimento delas (AsKew et al., 2000; JoHnson; Hoverstad, 2002). À medida que a aplicação for atrasada, há menor eficiência decontrole, pelo fato de as plantas daninhas apresentarem maior desenvolvimento vegetativo e tolerância aos herbicidas.

De maneira geral, os resultados obtidos para as duas espécies de braquiária, com relação aos valores de massa seca da parte aérea das plantas, confirmam os resultados das avaliações visuais de controle, ainda que as plantas submetidas ao herbicida sethoxydim tenham apresentado menor acúmulo de biomassa, quando comparadas àquelas tratadas com fluazifop-p-butil ehaloxyfop-methyl. Esse fato pode ser atribuído ao controle mais rápido proporcionado pelo herbicida sethoxydim e, consequentemente, à maior degeneração das plantas ao final das avaliações. A massa seca das plantas, da maneira como foi determinada, mostrou ser um bom parâmetro para avaliar a eficiência dos herbicidas testados. Verificou-se também que, em geral, $B$. decumbens apresentou resposta similar a B. plantaginea, em relação à toxicidade dos herbicidas testados.

\section{CONCLUSÕES}

Assim sendo, pode-se afirmar que, para ambas as espécies de Brachiaria estudadas, ofator determinante para o sucesso no controle foi o estádio de desenvolvimento das plantas no momento da aplicação, pois diversos pesquisadores relatam como de grande importância o conhecimento da relação entre o estádio de desenvolvimento e o uso de herbicidas em pós-emergência. Plantas mais desenvolvidas apresentam maiores barreiras à absorção de herbicidas e, consequentemente, maior capacidade derecuperação das injúrias causadas por esses produtos. Portanto, a eficiência do controle químico em pós-emergência, nas espécies de Brachiaria estudadas, foi dependente do estádio de desenvolvimento da planta.

\section{AGRADECIMENTOS}

À Fundação de Amparo à Pesquisa do Estado de São Paulo pela concessão de bolsa à primeira autora e financiamento da pesquisa.
AKIN, D.E.; CHESSON, A. Lignification as the major factor limiting forage feeding value specially in warm conditions. In: INTERNATIONAL GRASSLAND CONGRESS, 16., 1989, Nice, França. Proceedings. Nice: Association Francaise pour la Production Feurragere, 1989. p.1753-1760.

ASKEW, S.D.; SHAW, D.R.; STREET, J.E. Graminicide application timing influences red rice (Oryza sativa) control and seedhead reduction in soybean (Glycine max). Weed Technology, v.14, p.176-181, 2000.

CARVALHO, S.J.P.; BUISSA, J.A.R.; NICOLAI, M.; LÓPEZ-OVEJERO, R.F.; CHRISTOFFOLETI, P.J. Suscetibilidade diferencial de plantas daninhas do gênero Amaranthus aos herbicidas trifloxysulfuron-sodium e chlorimuron-ethyl. Planta Daninha, v.24, p.541-548, 2006.

CHAMEL, A. Foliar uptake of chemicals studied with whole plants and isolated cuticles. In: NEUMANN, P.M. (Ed.). Plant growth and leaf-applied chemicals. Boca Raton: CRC Press, 1988. p.27-50.

CRAWFORD, K.M.; ZAMBRYSKI, P.C. Non-targeted and targeted protein movement through plasmodesmata in leaves in different developmental and physiological status. Plant Physiology, v.125, p.1802-1812, 2001.

FLECK, N.G.; VARGAS, L.E.; CUNHA, M.M. Controle de plantas daninhas em soja com doses reduzidas de herbicidas. Planta Daninha, v.13, p.117-125, 1995.

FLECK, N.G.; CUNHA, M.M. VARGAS, L. Dose reduzida de clethodim no controle de papuã na cultura da soja, em função da época de aplicação. Planta Daninha, v.15, p.18-24, 1997.

FLECK, N.G.; LAZAROTO, C.A.; SCHAEDLER, C.E.; FERREIRA, F.B. Controle de papuã (Brachiaria plantaginea) em soja em função da dose e da época de aplicação do herbicida clethodim. Planta Daninha, v.26, p.375-383, 2008.

JOHNSON, G.A.; HOVERSTAD, T.R. Effect of row spacing and herbicide application timing on weed control and grain yield in corn (Zea mays). Weed Technology, v.16, p.548-553, 2002.

MOHLER, C.L. Enhancing the competitive ability of crops. In: LIEBMAN, M.; MOHLER, C.L.; STAVER, C.P. (Ed.). Ecological management of agricultural weeds. Cambridge: Cambridge University Press, 2001. p.269-322.

NAZARKO, O.M.; VAN ACKER, R.C.; ENTZ, M.H. Strategies and tactics for herbicide use reduction in field crops in Canada: a review. Canadian Journal of Plant Science, v.85, p.457-479, 2005.

RIZZARDI, M.A.; FLECK, N.G. Dose econômica de acifluorfen + bentazon para controle de picão preto 
e guanxuma em soja. Planta Daninha, v.22, p.117-125, 2004.

SMEDA, R.J.; PUTNAM, A.R. Influence of temperature, rainfall, grass species, and growth stage on efficacy of fluazifop-p-butil. Weed Technology, v.4, p.349-355, 1990.
VIDAL, R.A.; PORTES, E.S.; LAMEGO, F.P.; TREZZI, M.M. Resistência de Eleusine indica aos inibidores de ACCase. Planta Daninha, v.24, p.163-171, 2006.

Recebido em 9/6/10

Aceito em 28/4/11 